\title{
Upgradation of Conventional Commercial Greenhouse Using Climate Control Module to Reduce Energy Consumption
}

\author{
M.C. Subin ${ }^{1, *}$, R. Karthikeyan ${ }^{1}$ \\ ${ }^{I}$ Department of Mechanical Engineering, Birla Institute of Technology and Science, Dubai P. O. Box No. - 345055,UAE.
}

\begin{abstract}
With the advent of greenhouse technology, farmers can control the growing environment for optimal agricultural productivity. However, greenhouses are expensive facilities with a limited lifespan. Therefore, to achieve maximum productivity, and hence, return on investment, farmers must operate these structures efficiently. Various technologies have been developed to facilitate automatic control of greenhouse tools and equipment to achieve the best temperature, humidity, and soil moisture. Two most common methods include the conventional timer and an automatic control unit that has an climate control strategy (CMS). The latter comprises a programmable logic controller that can obtain and analyze information from weather and soil sensors using a set of instructions written on its microcontroller. A Bluetooth module facilitates wireless communication and remote control using CMS. A study was conducted to compare the two control systems. The experimental research that ran for two weeks involved growing microgreens - carrot in greenhouses fitted with the control systems. Analysis of data using control grouping, called ANOVA, revealed significant differences, indicating better greenhouse control and performance with ICS compared to the conventional timer control. Plants grown in greenhouses fitted with CMS recorded better performance in terms of height, number of leaves, dry matter weight, fresh matter weight, and temperature control. Furthermore, CMS can achieve up to $30 \%$ savings on water and electricity. The obtained temperature controls were verified using CFD.
\end{abstract}

Key words : Greenhouse farming, Evaporative coolers, climate control systems, CFD

\subsection{INTRODUCTION}

A greenhouse is an agricultural structure meant to protect crops from external dangers including fungi, insects, pests, rodents, and birds. In addition, these structures provide farmers with an opportunity to control the growing environment for optimal crop production while improving the quality of the produce. A greenhouse comprises a transparent plastic sheet of paper that a farmer erects over a rigid structural frame in an effort to create an internal environment while allowing for entry of sunlight.

Greenhouses are costly facilities. To save on electricity and water costs while preventing soil hardness and offer best control of the environment, remote controlled network systems are extensively applied in commercial greenhouses[1].Upgraded technology usually comprises a detailed communication using a wireless local area network. Therefore, it is possible to send wireless signals from a remote or mobile device such as a smartphone. However, the wireless systems have limited geographical coverage or distance, through which it is possible to send a signal. In most cases, the distance usually ranges from 10 to $20 \mathrm{~m}$ depending on the device type, which determines the signal strength[2].

Radio waves are used to create a connection between a climate control system (CMS) and an output systems like a laptop or smart phone can be used. CMS is essentially a computer comprising a motherboard capable of processing information and Bluetooth radio, which enables the system to connect, and hence, share information with others[3]. Bluetooth devices usually share information or communicate through piconets, which are short-range, ad hoc networks. The network has limitation with respect to the number of devices that one can connect. Usually, piconets allow a maximum of eight devices connected simultaneously[3]. Connection between two Bluetooth devices does not require installation or setup. Instead, creation of a piconet results in one of the Bluetooth devices taking up the master role while all others assuming slave positions. These wireless networks or piconets can be used for greenhouse control.

Massive water usage for agriculture affects the ground water systems [4,25] has tempted humans to use greenhouse farming with a precise water consumption control. Most of the irrigation water utilization originates from underground sources, resulting in the over-exploitation of underground water layers[5]. To avoid the over-exploitation of ground water in agriculture, the only way is to control the water usage based on the frequencies required for the crop growth, and automatic irrigation control will play an important role in this $[6,7,8,1]$ Optimal water management is important for plant growth, and therefore, a defined hydraulic balance is important for a better yield with an efficient water management system[8,9]. The analysis of water management must be carefully conducted by incorporating all parameters that control the water content in soil and diffusion of the same to various part of the plant for an adequate growth[10]. The automatic irrigation system is the only way to produce effective plant growth with minimal water usage. Recently, researchers have studied the feasibility of programmable logic controller (PLC )-based irrigation controllers for defining actuators[11] and movement in line with the water demand consumption[12].Advanced studies have been conducted with control algorithms[13] and a feedback-controlled system with water absorption has been used as a feedback measure. Sophisticated control strategies with more than one sensor have been proposed to balance the yield and efficiency[14] .Recently, a predictive control model with the measure of soil moisture content has been proposed[15]. 


\subsection{AUTOMATIC CLIMATE CONTROL SYSTEMS FOR COMMERCIAL GREENHOUSES}

Most of the greenhouse control systems are limited in controlling the operations in a sequence of time, but do not perform proper control with on/off functions within a required interval. Despite the classical approach with limited feedback for the resources, adequate approaches have been proposed with hydro balance in line with the substrate water balance [10]. An event-based control system was developed to achieve a better result, which is directly related to water consumption as per the plant demand for optimal growth [16]. Virtual sensors[17] have been used in some of the vent-based models, in order to control the water usage. A detailed simulation model[18] was developed using the water control algorithm, but its drawback lies in the control of the soil moisture content.

Radio waves are used to create a connection between a CMS and a computer or a mobile device, such as a smartphone or tablet. A CMS is essentially a computer comprising a motherboard capable of processing information and a Bluetooth radio, which enables the system to connect, and hence, share information with others[3].Bluetooth devices usually share information or communicate through piconets, which are short-range, ad hoc networks. The network has limitation with respect to the number of devices that one can connect. Usually, piconets allow a maximum of eight devices connected simultaneously[3]. Connection between two Bluetooth devices does not require installation or setup. Instead, creation of a piconet results in one of the Bluetooth devices taking up the master role while all others assuming slave positions. Therefore, a piconet allows a maximum of seven slaves since one device becomes the master. It is expected that some devices will leave, while others will enter the network. Therefore, piconets are not static but dynamic and configuration occurs automatically without the knowledge of users. It is possible to use these wireless networks or piconets for greenhouse control.

The applicability of Bluetooth technology to agricultural production is a research area of interest.

Kim et al[19] developed system which can sense the feedbacks from the soil and indoor weather using filed devices and interfacing the commands to the central station using Bluetooth technology. To close the circuit, the feedback loop is connected to a system of linear sprinklers, controlled by a programmable logic controller (PLC). The PLC processes feedback information from the base system to vary water irrigation, in order to achieve the desired moisture level [20].

Green plants require sunlight, soil, and water for growth and production. In addition, it is imperative to maintain an optimum temperature within the greenhouse, for maximum production. Too little water or too much of it is counterproductive. Therefore, it is imperative to control the water supply to ensure that the plants have just enough of it while preventing wastage. There are various irrigation systems, but the drip method is the most preferred because of the ability to conserve water[21] (Adeyemi et al., 2017). In addition, it is possible to control with high levels of precision.

Researchers have investigated the efficiency of drip irrigation [22] investigated the efficiency of drip irrigation in a greenhouse growing cherry tomatoes. Analysis of the collected data indicated that the irrigation method or system was associated with a significant reduction in fruit cracking ratio, while the total soluble solids in the tomatoes increased when little water was used for irrigation[22]. In another study,[23]) sought to investigate the benefits of fertigation, which involves applying fertilizers using the drip irrigation system. The study results indicated that fertigation has the potential to increase the quality of cut flowers while saving on fertilizers and [23]). These study findings show numerous benefits of drip irrigation.

There are various ways of controlling water supply or irrigation. Farmers usually water their crops in the morning or afternoon, to ensure that there is enough soil moisture. Timers can also be used to switch on and off drip irrigation systems, thereby controlling water supply. The crop water stress index (CWSI) of the crop can also be used to make decisions regarding water supply. CWSI helps a farmer to determine the best soil moisture level to support optimum plant growth and crop production based on the potential evaporation. The crop variety determines the calibration curves. Furthermore, following a systematic process helps in avoiding measurement errors, thereby ensuring high levels of accuracy for maximum productivity [24]. However, it is possible and simpler to use air temperature and soil moisture sensors to help in making irrigation-based decisions without the use of CWSI calibration curves. Indeed, temperature and soil moisture are the main factors of CWSI.

Environmental control also plays a critical role in greenhouse production. If properly conducted, it provides crops with a good microclimate. Important elements of consideration in greenhouse environmental control include temperature, radiation, and humidity. Control tools include shading, fans, and vents. Farmers can control these environmental factors independently. However, note that environmental factors have important interactions[1].Therefore, it is vital to develop integrated or intelligent control units that use multiple sensors and a control unit to process information, and hence, make control decisions based on an established algorithm that considers possible interactions [1].An adaptive control unit would facilitate real-time determination of the microclimate for optimal output. The current study seeks to integrate environmental sensors, drip irrigation system, PLC, and wireless devices to construct an intelligent climate control system for use in greenhouses. The objectives of the study are stated below.

1) Concept design and verification of drip irrigation through collection and processing of data on ambient temperature, relative humidity, moisture content in the soil, and indoor-air velocity

2) Integration of CMS with PLC-based timer in controlling the greenhouse microclimate for producing Romaine lettuce and similar crops

3) Concept design and design verification using computational fluid dynamics (CFD) of the automatic CMS module using a wireless network

4) The study sought to compare the economics of greenhouse operation when using CMS and PLC-based timers. 


\subsection{MATERIALS AND METHODS}

Commercial greenhouse climate system is mainly equipped with a central control module to interface the filed devices to control various controlled parameters. Individual evaporative coolers and the exhaust fans are also interfaced with the central control system. Irrigation and fertigation systems has been integrated with necessary field devices to trigger the system as per the demand. Current study is analyzing the microclimate upgradation of the greenhouse by controlling the irrigation related variables and the control variables which are controlling the HVAC (Heating Ventilation and Air-conditioning) systems such as temperature and relative humidity. Crop yield has been verified with respect to the ideal parameters for the irrigation controlled scenario and the temperature as well as relative humidity of the upgraded system has been verified using computational fluid dynamics renderings.

\subsection{STRATEGY FOR MICROCLIMATE CONTROL FOR IRRIGATION CONTROL}

This study used various sensors to determine the microclimate conditions. EE-10 (Elektronik) helped in obtaining information about temperature and relative humidity, while JLP02-TR (TOHO) was used for radiation sensing. An integrated module that can control and perform self-adjustments of the set parameters, such as ambient temperature and moisture content in air, is an innovative approach for this study, exclusively using the automated climate control module. The author determined an equation used for calibration by using sensor specification. The calibration equation is useful in developing the control strategy installed on the host station (a personal computer shown in Figure 1) and in-built in the microcontroller. Therefore, environmental data under consideration included air temperature (T), soil moisture (M), solar radiation $(\mathrm{S})$, and relative humidity $(\mathrm{RH})$.

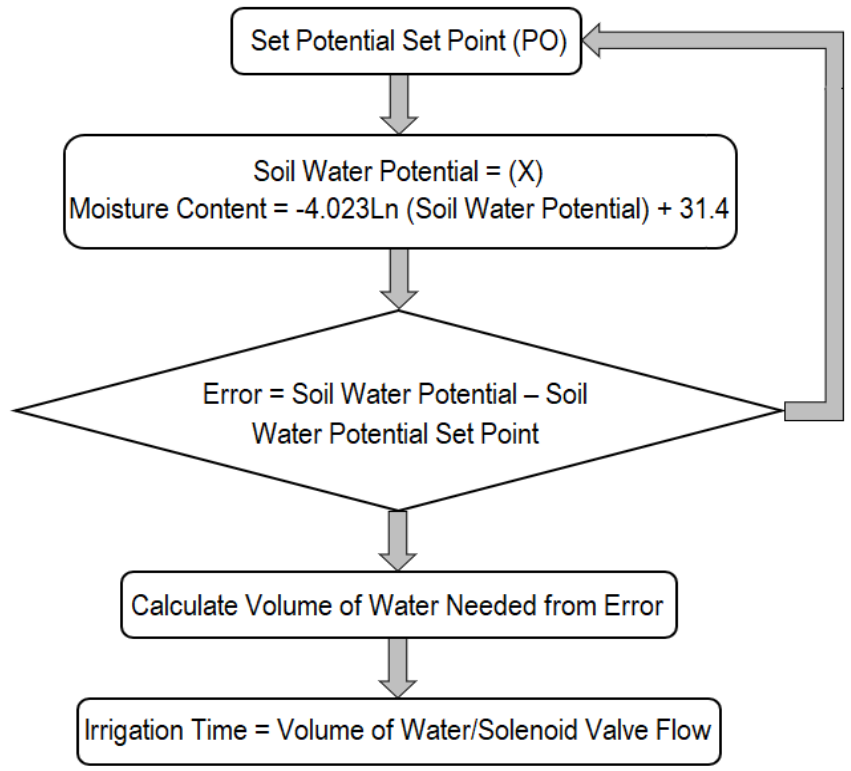

Figure 1: Schematic showing the control system logic used for controlling the greenhouse microclimate

The drip irrigation kit comprised a water tank, a nutrient tank, a pump, valves, and a ratio adjustor. The pump pushed water and nutrients from their respective tanks to the plants via the drip nozzle, main pipe, and micro pipe. Control of water supply was possible through adjustment of the number of nozzles, lateral nozzle distance, and the pump working duration (PWD). The author conducted a calibration experiment, which involved determination of the amount of water and changes in moisture content in soil (MC) for WDP within 2, 4, 8, 16, 20, and 25 min. Table 1 shows the experimental results.

Table 1: Results of the calibration experiment

\begin{tabular}{|c|c|}
\hline PWD $(\min )$ & SMC in $(\%)$ \\
\hline 2 & 2.38 \\
\hline 4 & 5.26 \\
\hline 8 & 9.86 \\
\hline 16 & 17.65 \\
\hline 20 & 21.22 \\
\hline 25 & 26.68 \\
\hline
\end{tabular}

Data plotting produced a linear curve, as shown in Figure2. The resulting equation is only applicable before reaching the soil saturation level. The nutrient tank contained iGarden, which was mixed using a ratio of one part in every 5000 parts of water. The water was then used for irrigating the plants on the two benches. A commercial growth medium (7-03, Dayi Argitech Corporation) was used for plant growth. A brief control system lock diagram has been shown in the figure 3 which is dictating the correlation between the moisture sensing and the pump ON or OFF command directly.

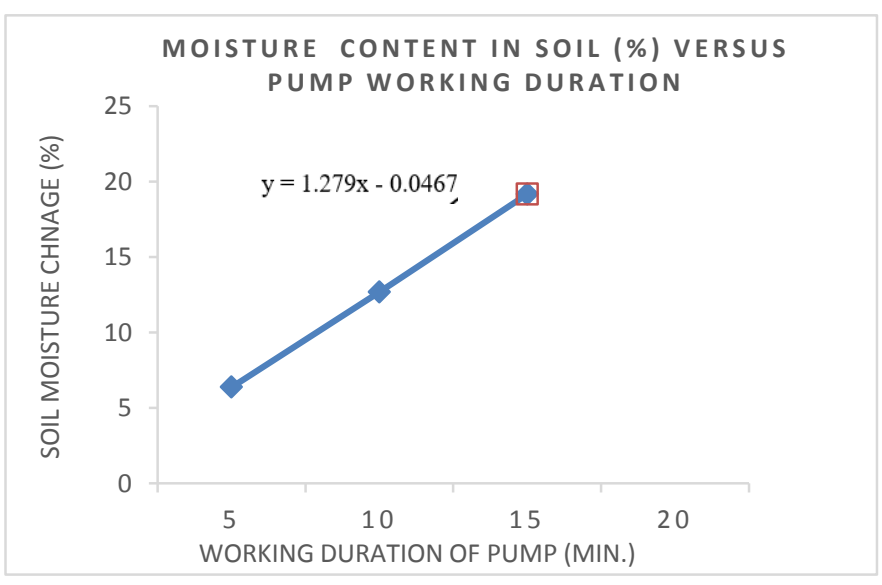

Figure 2: Relation between pump working duration and soil moisture

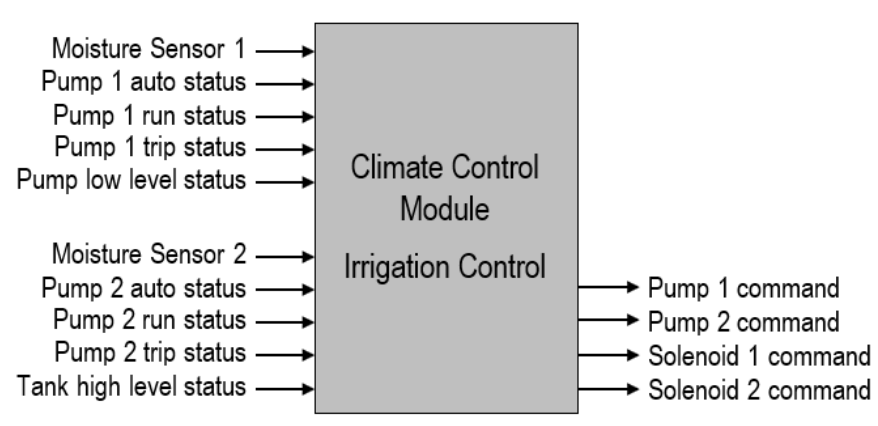

Figure 3: Control block showing inputs and outputs 
International Journal of Engineering Research and Technology. ISSN 0974-3154, Volume 13, Number 7 (2020), pp. 1709-1723

(C) International Research Publication House. https://dx.doi.org/10.37624/IJERT/13.7.2020.1709-1723

2.2 STRATEGY FOR MICROCLIMATE CONTROL TO CONTROL RELATIVE HUMIDITY, TEMPERATURE AND SOIL MOISTURE CONTENT.

The control model involved inputs from multiple sensors, information processing using in-built logic, and production of a single output. The input data included T, S, RH, and M, while the output comprised the amount of water adjustment based on the WDP formula. As shown in Figure 4, there are three levels of each input factor meant to represent the various microclimate conditions.

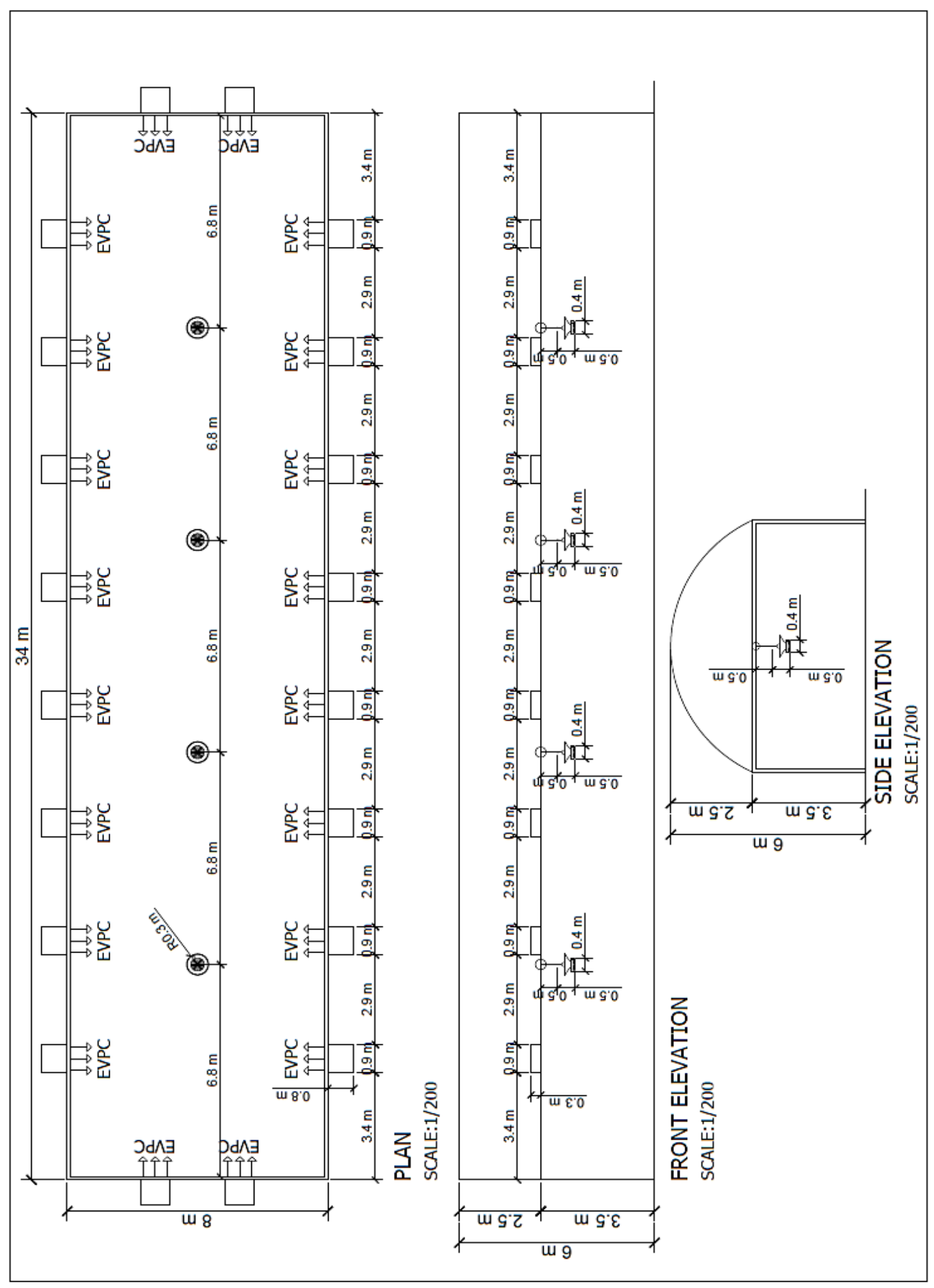

Figure 4. Plan of the greenhouse mounted with evaporative coolers (EVPC - Evaporative coolers) 
It is possible to produce two datasets when the moisture level is medium. At low moisture level, three datasets were generated. No irrigation occurred when the soil moisture was high, to avoid saturation or flooding. The logged data were transferred to the central server using the interactive logger chip system, which was programmed using the microprocessor application from the building management system's DDC controller using the Niagra platform. Wi-Fi connections were built to create a communication link between the personal computer and the microcontroller, which then conveyed output information to a PLC relay to control the PWD of the climate control system.

\section{TEST SETUP AND DESIGN}

The test was conducted in two rows in a rack system, with each rack having four lines with ready-for-nursery seeds of Microgreen carrot. Therefore, there were 64 plants. The researcher marked one of the benches as the test group, while the other one comprising 32 seedlings was the control group, as shown in Figures 5 and 6 . The test group received irrigation control using the work in house, while a PLC-based timer was used for the control group. In the control group, the timer was set to start the pump at 7:00 am and allow it to run for $15 \mathrm{~min}$. The experiment ran for two weeks. The existing green house (34 m (L) x $8 \mathrm{~m}(\mathrm{~W}) \times 6 \mathrm{~m}(\mathrm{H})$ was upgraded with box-type evaporative coolers, each having $2800 \mathrm{cfm}$.

Another experiment was conducted on the test group, which lasted for one month. RH is a function of soil moisture and temperature. Mathematically, $\mathrm{RH}=£(\mathrm{~T}, \mathrm{M})$. Therefore, in order to maintain the desired $\mathrm{RH}$, one can adjust the water supply or temperature. It has been established that microgreens- carrot perform the best within an $\mathrm{RH}$ range between $55 \%$ and $65 \%$. Therefore, the goal was to ensure that relative humidity was within this range. In this experiment, pumping was conducted for 10 min when RH was less than 55\%. However, the water supply time was reduced to 5 min when the RH was between $55 \%$ and $65 \%$. In addition, we endeavored to maintain temperature between $18^{\circ} \mathrm{C}$ and $21^{\circ} \mathrm{C}$. The author determined and recorded data on height and number of leaves once per week. Upon harvesting the crops, the author obtained fresh and dry weights.

\subsection{TEST SETUP}

Test has been carried out in the in Al Khawaneej District in the Emirate of Dubai in United Arab Emirates.

A running single span greenhouse was equipped with all the necessary field devices as well as the control systems. A mobile dehumidifier was used in some point of time to balance the humidity inside the system. The researcher tested the climate control module with the microcontroller in the sensing unit for validation and evaluation of its efficiency in transmitting data. Testing was conducted for five locations on the field as shown in figure 7. Testing was conducted for one hour during the day and one hour at night. The CMS used for data transmission had signal coverage of $100 \mathrm{~m}$ at $15 \mathrm{dBm}$ output at a frequency ranging between 2402 and $2480 \mathrm{MHz}$. Physical barriers such as buildings and trees usually lower the signal strength. Therefore, the researcher strived to obtain the best location for the CMS module with minimal transmission interference.

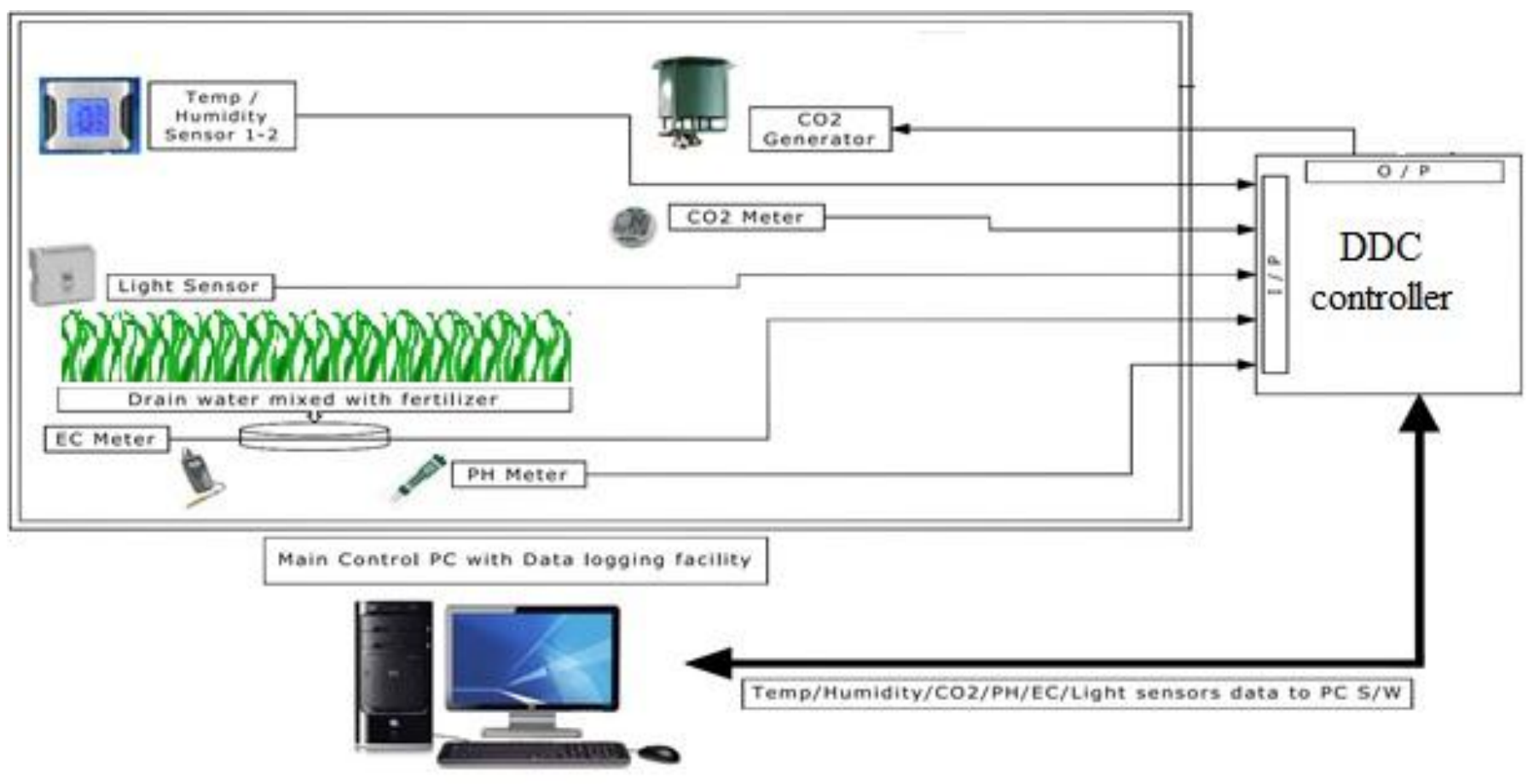

Figure 5: Setup of the climate control 


\subsection{WIRELESS RELAY OF SIGNAL AND INFORMATION IN THE GREENHOUSE USING CMS}

In this study, five possible points were tested within the greenhouse for locating the CMS. The distance between the sensor unit and CMS ranged between 6 and $26 \mathrm{~m}$. Besides distance, physical barriers such as brick walls, wooden posts, glass sheets, polythene covers, and plants hinder effective transmission of wireless signals through reflection, refraction, or absorption. Therefore, it is important to consider these issues when determining the point of locating the CMS unit. Only the furthest point recorded zero percent transmission rate, while all others recorded $100 \%$. Therefore, it was decided to place the CMS closest to the sensing unit for maximum transmission of signals via Bluetooth.

\subsection{GREENHOUSE MICROCLIMATE THROUGHOUT THE EXPERIMENTAL PERIOD}

For the first experiment, which lasted for two weeks or $336 \mathrm{~h}$, the temperature ranged between $18.2^{\circ} \mathrm{C}$ and $22.6^{\circ} \mathrm{C}$. RH ranged between $49.7 \%$ and $66.7 \%$, irrigation pump working "ON" duration has been analyzed various occasions in the cycle of experiment between the day and night. Only very few time the pump triggered up to 3 minutes and in all the other period the maximum pump working duration was in minute, this is stating the efficiency of the new scheme of climate control arrangement. One of the major advantages of controlled agriculture is the constant yield of the crops with a less irrigation and other commercial energy consumptions. As shown in Figure 9, the pump was ON for seven periods. Soil moisture was high most of the time under the prevailing water moisture conditions. Therefore, there was no need to run the pump for $10 \mathrm{~min}$ in several instances; a continuous interval has been observed and the results recorded in

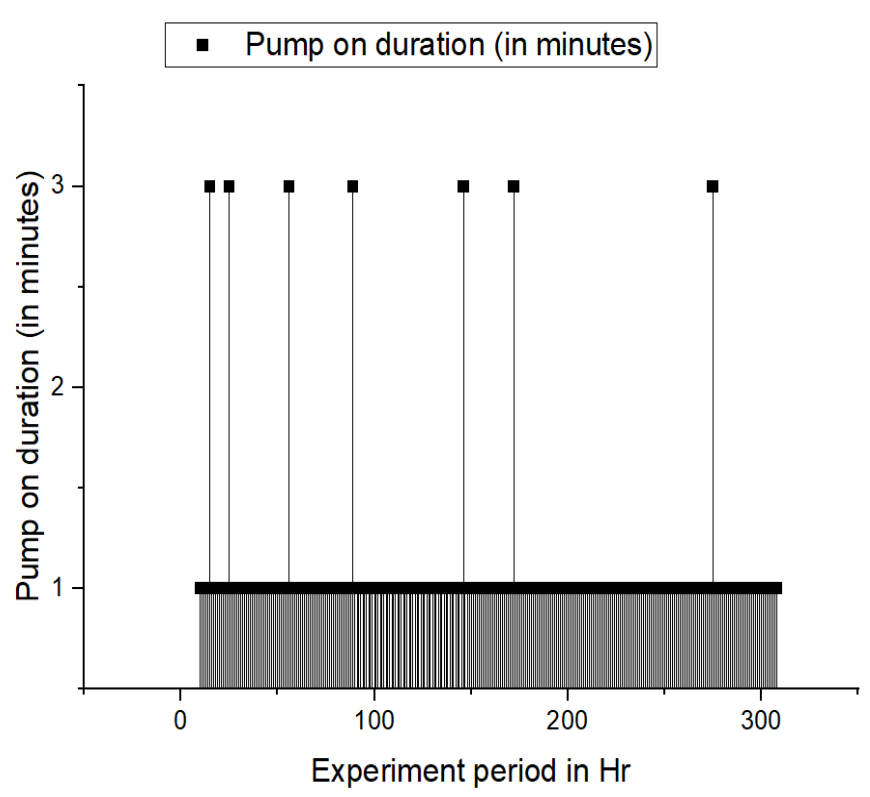

Figure 6: Pump testing results

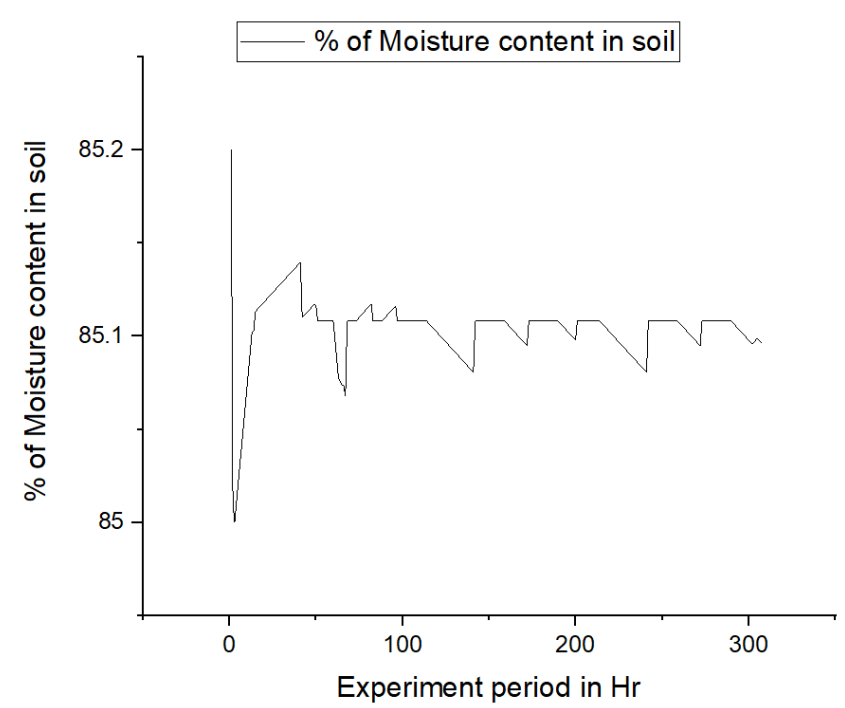

Figure 7: Changes in soil moisture during the first experiment

\subsection{GROWTH OF PLANTS}

All the volumetric, as well as the leaf, quality for the plants in the two racks was recorded after the end of the experiment. To obtain dry weight, all plants were dried at $70^{\circ} \mathrm{C}$ for almost 48 h. Table 2 shows the mean value for each variable. Data on fresh and dry matter weight for week 1 are not available since we did not harvest the plants by the end of the week. The ANOVA test shows a significant difference between the two means at $95 \%$ confidence interval. Yield comparison in the test and controlled environment has been comprehended in the Table2.

Table 2: Comparison between test and control groups on plant properties.

\begin{tabular}{|l|c|c|c|c|}
\hline Week & \multicolumn{2}{|c|}{1} & \multicolumn{2}{c|}{ T } \\
\hline Group & Test & Control & Test & Control \\
\hline $\begin{array}{l}\text { Height of } \\
\text { the plant } \\
\text { (mm) }\end{array}$ & 15.1 & 14.8 & 22.9 & 21.7 \\
\hline $\begin{array}{l}\text { Number of } \\
\text { leaves }\end{array}$ & 6 & 5 & 9 & 7 \\
\hline FW (g) & - & - & 18.4 & 16.3 \\
\hline DW (g) & - & - & 0.94 & 0.79 \\
\hline
\end{tabular}

A detailed plant growth analysis has been carried out in the subsequent cycle of arrangement in the controlled environment and analyzed that the plant height was quite closer to ideal height. A comparative chart between the ideal and actual plant height is annotating below in Figure 10 and the actual images of the Microgreen carrot at the $7^{\text {th }}$ day is shown in the figure 11 . 
International Journal of Engineering Research and Technology. ISSN 0974-3154, Volume 13, Number 7 (2020), pp. 1709-1723

(C) International Research Publication House. https://dx.doi.org/10.37624/IJERT/13.7.2020.1709-1723

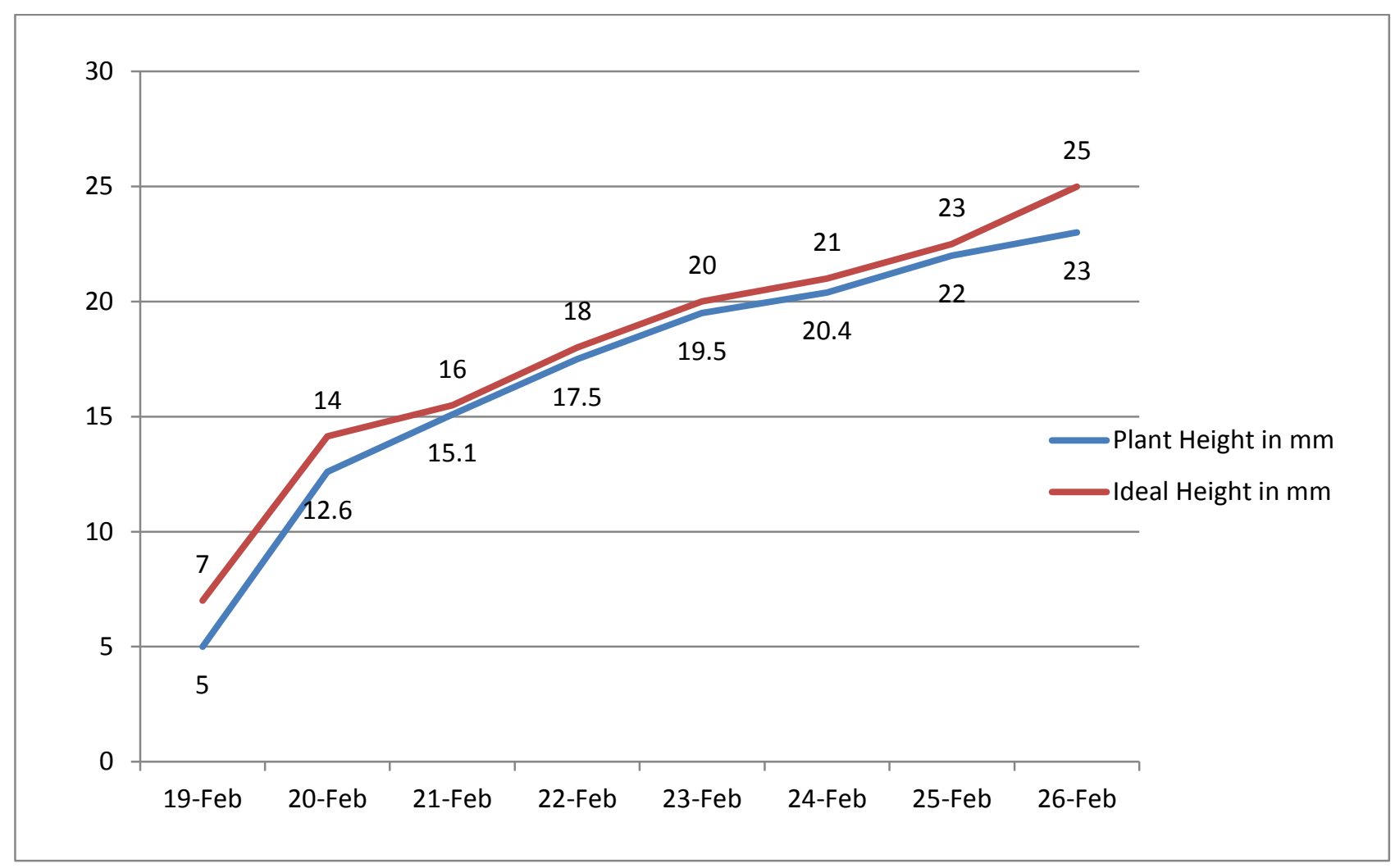

Figure 8: Plant growth analysis

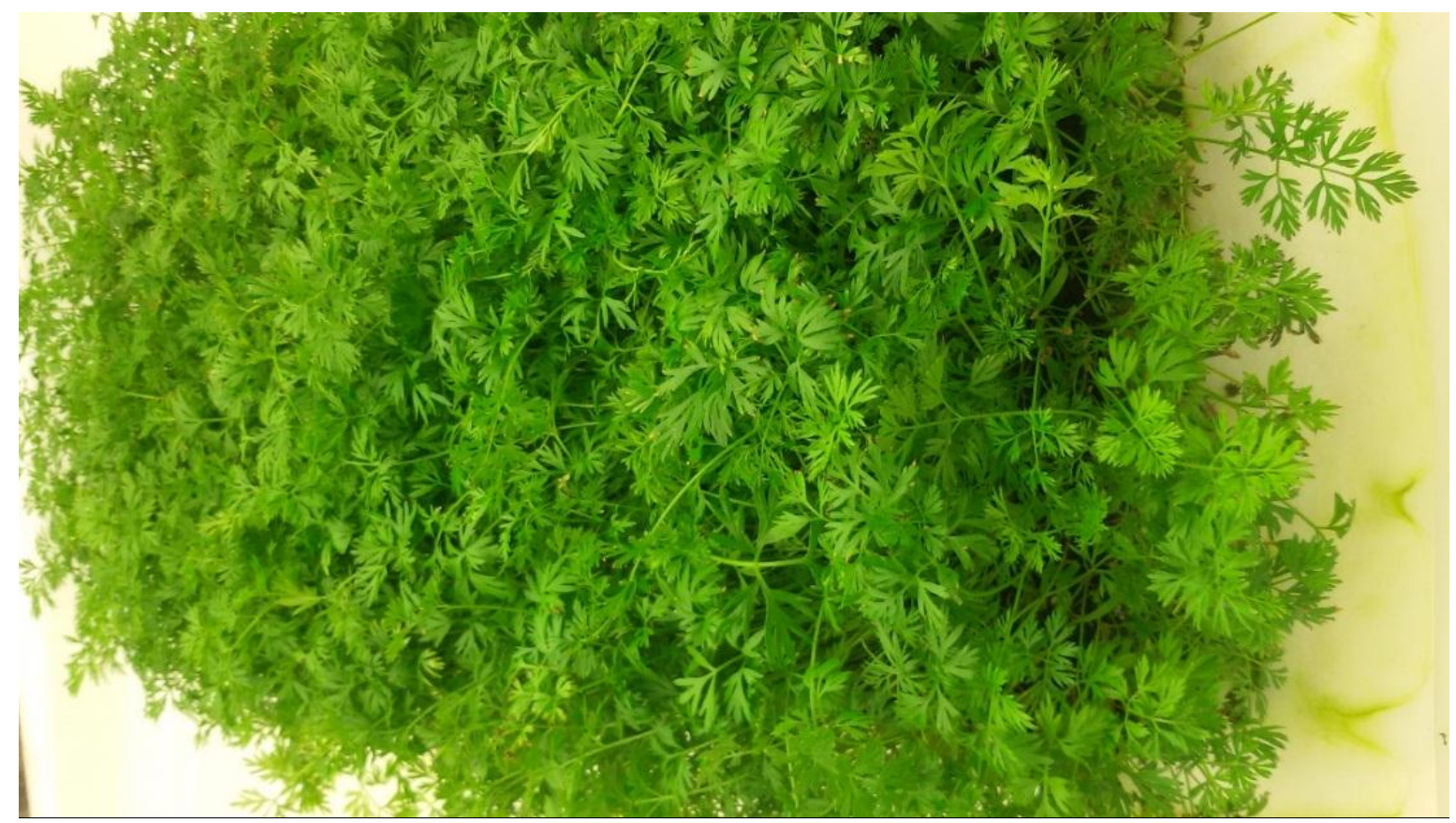

Figure 9(a): Microgreen harvested at $6^{\text {th }}$ Day 
International Journal of Engineering Research and Technology. ISSN 0974-3154, Volume 13, Number 7 (2020), pp. 1709-1723

(C) International Research Publication House. https://dx.doi.org/10.37624/IJERT/13.7.2020.1709-1723

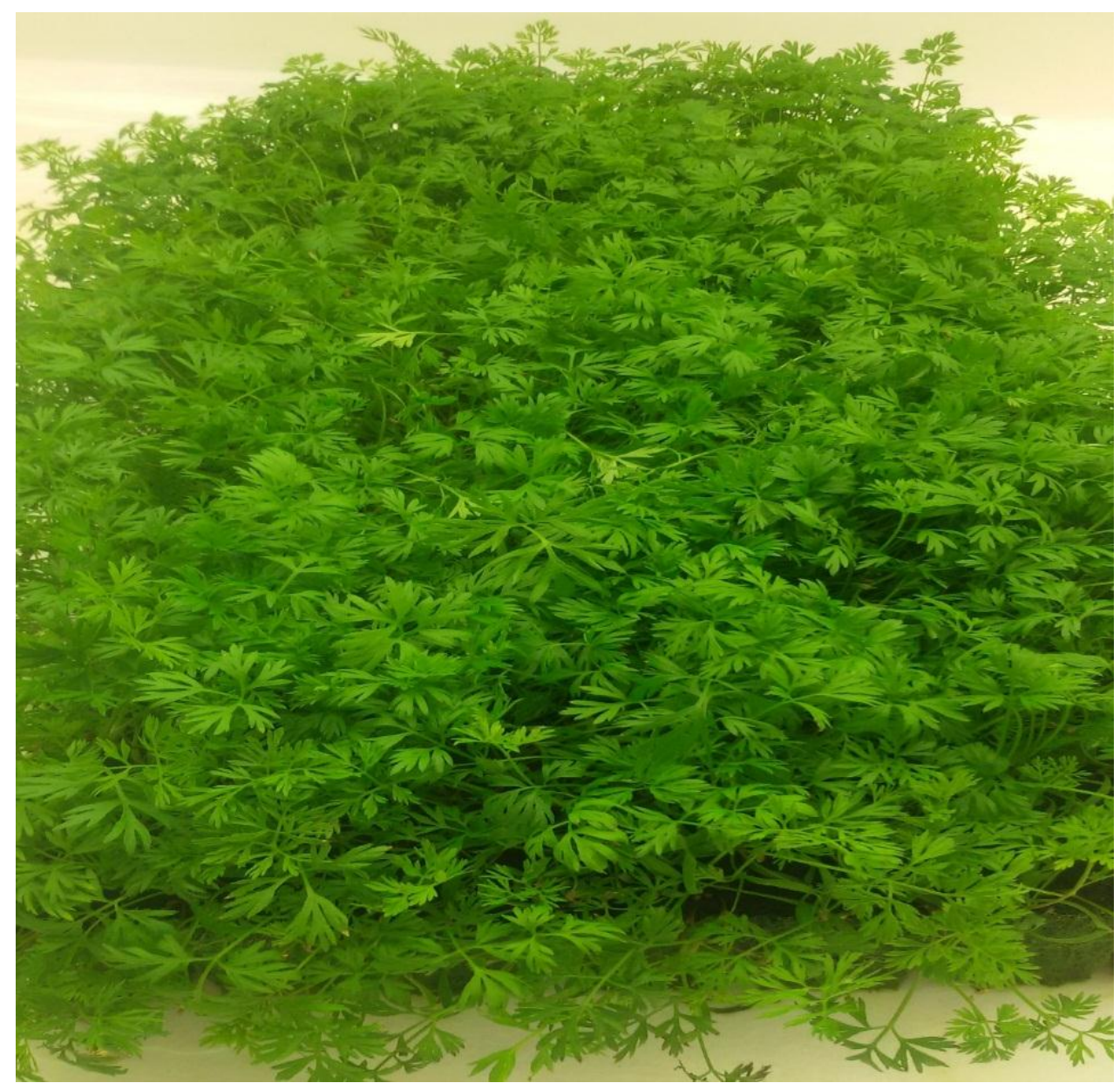

Figure 9(b): Microgreen harvested at $8^{\text {th }}$ Day

\section{COMPARISON OF ECONOMIC VARIABLES}

Electricity and water were the main economic variables used. The pump used was electric. Therefore, the longer it ran, the more electricity was used. The researcher recorded $21 \mathrm{~min}$ of pump operation for the test group. The control group recorded
$3.5 \mathrm{~h}$ of operation throughout the two weeks the experiment was conducted. In the second experiment, the operation time was $412 \mathrm{~min}$ and $710 \mathrm{~min}$ for the test and control groups, respectively. Table 3 summarizes the results. As shown, the integrated CMS reduced water and energy consumption by 90\% compared to a PLC-based timer.

Table 3: Pumping time, water, and electricity use data

\begin{tabular}{|c|c|c|c|c|c|c|}
\hline \multirow{2}{*}{ Experiment } & \multicolumn{3}{|c|}{ Test Group } & \multicolumn{2}{c|}{ Control Group } \\
\hline & $\begin{array}{c}\text { Pump running } \\
\text { time }\end{array}$ & $\begin{array}{c}\text { Water } \\
\text { consumption (cc) }\end{array}$ & $\begin{array}{c}\text { Electricity } \\
\text { used (kW-h) }\end{array}$ & $\begin{array}{c}\text { Pump } \\
\text { running time }\end{array}$ & $\begin{array}{c}\text { Water } \\
\text { consumption (cc) }\end{array}$ & $\begin{array}{c}\text { Electricity used } \\
(\mathrm{kW}-\mathrm{h})\end{array}$ \\
\hline 1 & $21 \mathrm{~min}$ & 630 & 0.308 & $3.5 \mathrm{~h}$ & 6300 \\
\hline 2 & $412 \mathrm{~min}$ & 12,660 & 6.05 & $710 \mathrm{~min}$ & 21,900 & 3.08 \\
\hline
\end{tabular}




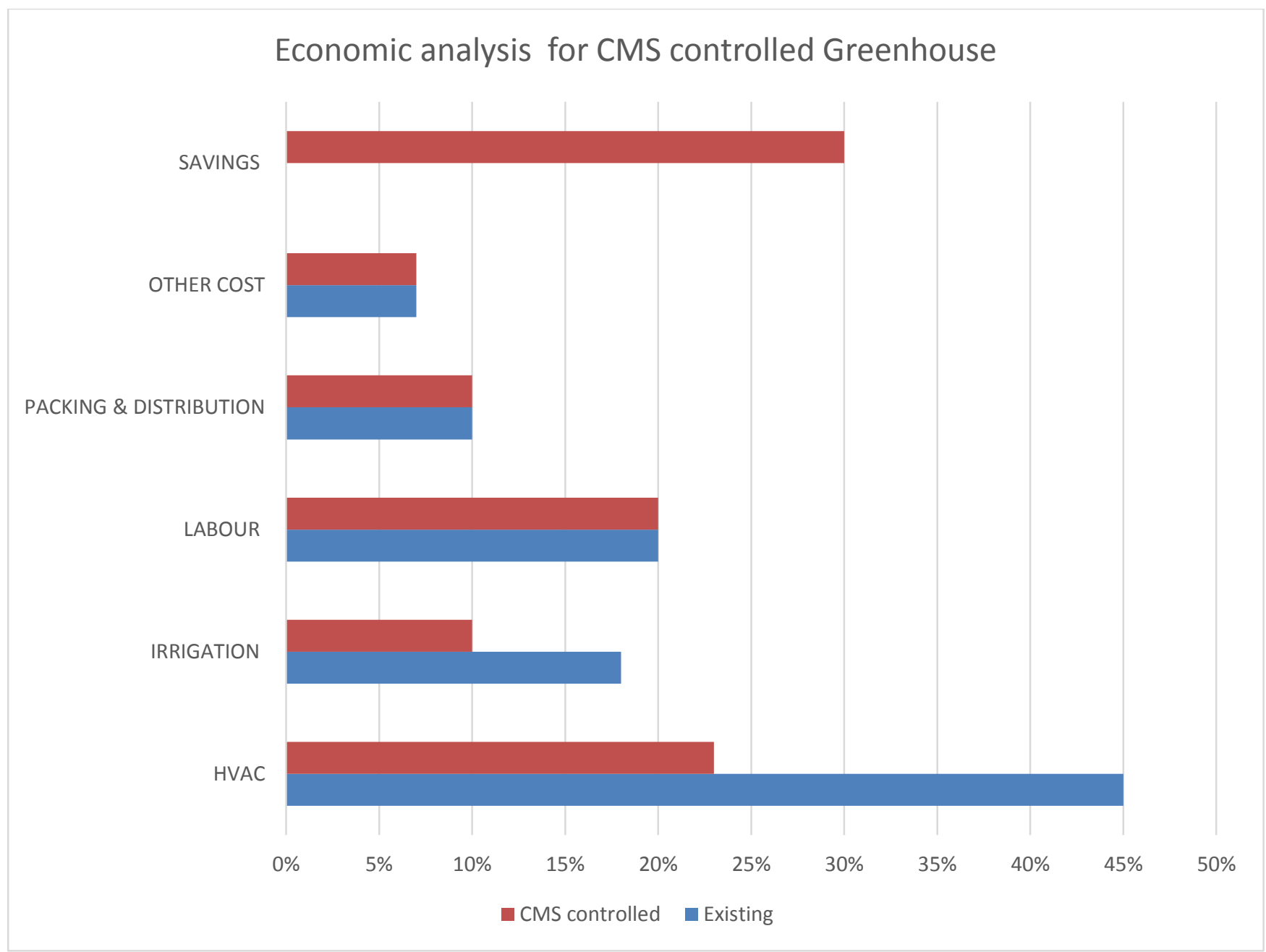

Figure 10: Economical analysis of the greenhouse (controlled versus conventional greenhouse farming )

An energy analysis has been carried out for this particular green house and found that the more than $45 \%$ of the total energy is using to run the HVAC systems to provide the necessary heating and cooling of the greenhouse is various season. Irrigation and labour component stands at second major cost driven elements. Scientifically calibrated climatic modules in consideration to the agronomical characteristics of the crop can provide good yield in a minimal duration.

\subsection{STUDY FINDINGS AND DISCUSSION OF RESULTS}

According to the findings, an integrated CMS facilitates the establishment of the desired greenhouse microclimate mainly because of its ability to control the environmental conditions with high levels of accuracy. The study findings also show that an integrated CMS incorporating a wireless signal to relay messages between the microcontroller and mobile device is highly effective in maintaining relative humidity, temperature, and soil moisture at the desired levels. The sensing unit comprises sensors for collecting vital data, and then sends it to the host, which contains an in-built algorithm for processing the data based on the necessary interactions. The host, which can be a smartphone, then sends the command to the microcontroller via a Bluetooth antenna or device for the execution of the command[26] (Ponce et al., 2015). Therefore, an integrated CMS provides real-time scanning of the greenhouse environment such that necessary changes are implemented continuously.

On the other hand, the conventional PLC-based timer is not logical. Instead, it executes a given command based on the input instructions[26] (Ponce et al., 2015). However, the provided instructions are static and based on the user's intuition, instead of the current environmental conditions. Therefore, there is a risk of the system switching ON the pump when the plants do not require water or switching OFF when the desired soil moisture is not achieved. Furthermore, there is potential for resource wastage when using the PLC-based timer, because of its inability to control the environment under the prevailing conditions.

The findings of the current study support the benefits of the integrated CMS over the conventional PLC-based timer. The outcomes of better microclimate control include improved crop yield and cost reduction[26] (Ponce et al., 2015). A comparison between the two groups showed that plants in the test performed better compared to those in the control group in terms of number of leaves, fresh matter, and dry matter. In 
addition, the study findings showed that greenhouses using integrated CMS achieve huge savings on water and electricity use, since the microcontroller switches the pump ON only when necessary.

However, the development of an integrated CMS is expensive. A good CMS plays a critical role in effective control of a greenhouse, and hence, ensures optimal production through maintenance of the best microclimate. When selecting the CMS, it is imperative to consider various issues or factors. Heat-load calculations facilitate decision-making regarding the equipment to use.

\subsection{VERIFICATION OF THE SYSTEM USING CFD}

CFD involves flow and thermal analysis. The process strives to ensure that one selects the best equipment for the desired load requirements. Therefore, it is imperative to study the application in order to define the problem, establish load requirements, and outline boundary conditions. Model testing helps in selecting the best equipment. Equations based on the simulations have been described, with the boundary conditions used for the simulations derived from the heat calculations (Tanny et al., 2008; López et al., 2012).

\subsection{BOUNDARY CONDITIONS FOR CFD VERIFICATION}

Boundary conditions were set for solving the computational output for the test setup. ANSYS FLUENT was used to verify the temperature variations during the automatic climate control operations. Detailed boundary conditions can be defined in correlation with various parameters, as per the heat-load calculations, which included the heat load from the structure of the greenhouse, human intervention, lighting, skylight, and supply and return diffusers. A summary of the solver setup has been annotated below.

Table 4: Summary of CFD setup parameters

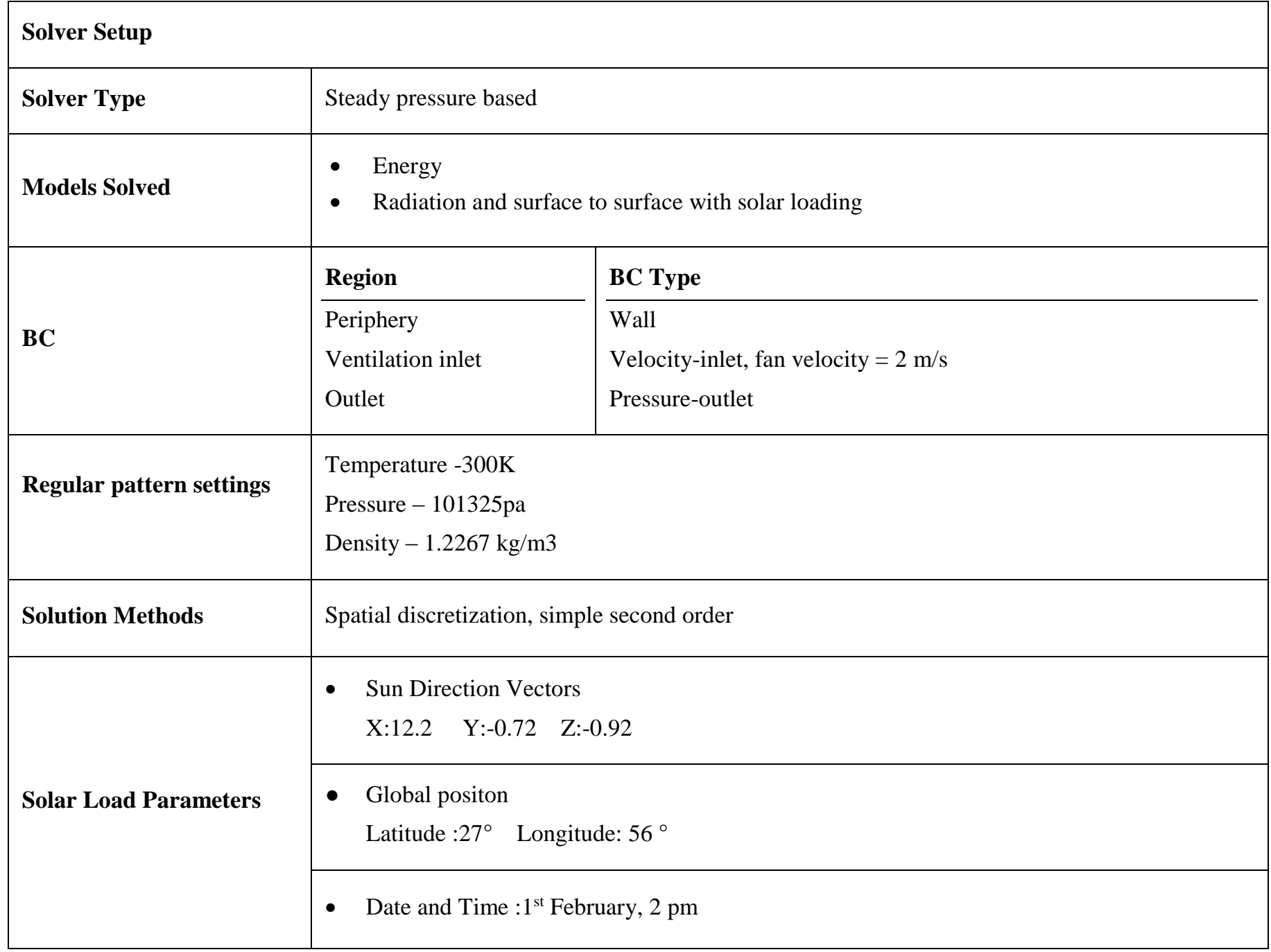


International Journal of Engineering Research and Technology. ISSN 0974-3154, Volume 13, Number 7 (2020), pp. 1709-1723

(C) International Research Publication House. https://dx.doi.org/10.37624/IJERT/13.7.2020.1709-1723

Human intervention inside the conditioned space for the commercial greenhouses equipped with the climate control module is considerably less, but a heat-load analysis of the same has been considered and the results are tabulated in Table 5.

Table 5: Boundary conditions for the heat load generated from humans

\begin{tabular}{|c|c|c|}
\hline \multicolumn{3}{|c|}{ Heat load from human } \\
\hline Parameter & Formulae & Value \\
\hline Surface area of floor for heat load & N/A & $272 \mathrm{~m}^{2}$ \\
\hline Total height of the space & Customized from end user & $6.0 \mathrm{~m}$ \\
\hline Total volume of atrium & Customized from end user & $1190 \mathrm{~m}^{3}$ \\
\hline Height of the plant occupation(H1) & HR1+HR2 & $2.0 \mathrm{~m}$ \\
\hline $\begin{array}{c}\text { Volume of ground floor( till 1.5 m for the plant) heat-load } \\
\text { distribution (V1) }\end{array}$ & A1XH1 & $408 \mathrm{~m}^{3}$ \\
\hline Heat Flux(Q/A) needs to be applied on roof & $(\mathrm{Q} / \mathrm{A})$ & $283 \mathrm{~W} / \mathrm{m}^{2}$ \\
\hline
\end{tabular}

Heat loads from the lighting are considerable due to the growth lights during the nighttime, for which the boundary conditions have been annotated below in Table 6 .

Table 6: Boundary conditions for the heat load generated from lighting

\begin{tabular}{|c|c|c|}
\hline \multicolumn{3}{|c|}{ Heat load generated from lighting } \\
\hline Parameter & Formulae & Value \\
\hline $\begin{array}{l}\text { Heat load from lighting and small power on } \\
\text { GF roof level (QL - GF) }\end{array}$ & $\begin{array}{l}\text { Customized from end user }\left(20 \mathrm{w} / \mathrm{m}^{2} \text { for }\right. \\
\left.\text { lighting and } 15 \mathrm{w} / \mathrm{m}^{2} \text { for small power }\right)\end{array}$ & $15785 \mathrm{~W}$ \\
\hline $\begin{array}{l}\text { Lighting }+ \text { small power distributed on ground } \\
\text { floor roof level (AL-GF). }\end{array}$ & Customized from end user & $56 \mathrm{~m}^{2}$ \\
\hline $\begin{array}{l}\text { Heat flux from lighting }+ \text { small power on } \\
\text { ground floor roof level }\left(\mathrm{Q}^{\mathrm{I}} \mathrm{L}-\mathrm{GF}\right)\end{array}$ & $\left(\mathrm{Q}^{\mathrm{I}} \mathrm{L}-\mathrm{MZ}\right) \quad$ '( $\left.\mathrm{A}^{\mathrm{I}} \mathrm{L}-\mathrm{MZ}\right)$ & $281.88 \mathrm{~W} / \mathrm{m}^{2}$ \\
\hline
\end{tabular}

Compared to the open-field cultivations, fewer sky light parameters are considered for greenhouse cultivations; however, direct solar impacts and the heat flux also need to be analyzed. The boundary conditions from the sky roof are summarized below in Table 7 .

Table 7: Boundary conditions for the heat loads from sky roof

\begin{tabular}{|c|c|c|}
\hline \multicolumn{2}{|c|}{ Heat loads from skylight roof } & Formulae \\
\hline Parameter & Customized from end user & $132.41 \mathrm{KW}$ \\
\hline Direct solar heat from roof (HR1) & Customized from end user & $7.71 \mathrm{KW}$ \\
\hline Conductive heat from roof (HR2) & Customized from end user & $46.0^{\circ} \mathrm{C}$ \\
\hline Outside temperature (DB) in worst condition (T1) & HR1+HR2 & $140.12 \mathrm{KW}$ \\
\hline Total heat load (Q) & Customized from end user & $495 \mathrm{~m}^{2}$ \\
\hline Total area of slanted roof (A) & (Q/A) & $283 \mathrm{~W} / \mathrm{m}^{2}$ \\
\hline
\end{tabular}


International Journal of Engineering Research and Technology. ISSN 0974-3154, Volume 13, Number 7 (2020), pp. 1709-1723

(C) International Research Publication House. https://dx.doi.org/10.37624/IJERT/13.7.2020.1709-1723

Headloads from the supply and return diffusers played an important role in the temperature distribution of the indoor ambient space of the greenhouse. The boundary conditions defined for the supply and return air diffuser are tabulated in Tables 8 and 9 .

Table 8: Boundary conditions for the air distribution and supply air diffuser

\begin{tabular}{|c|c|c|}
\hline \multicolumn{2}{|c|}{ Supply air diffuser boundary conditions } & Formulae \\
\hline Parameter & Value \\
\hline Area of each supply air diffuser(1 to 30)(As) & $(0.4 * 0.4 \pi) / 4$ & $0.12566 \mathrm{~m}^{2}$ \\
\hline Flow rate from each supply diffuser(1 to 30 Fs) & Customized from end user & $0.4 \mathrm{~m}^{3} / \mathrm{s}$ \\
\hline Velocity from each supply diffuser( 1 to 30 $)(\mathrm{Vs})$ & Fs/As & $3.18 \mathrm{~m} / \mathrm{s}$ \\
\hline Supply diffuser air temperature(DB) & Customized from end user & $17^{\circ} \mathrm{C}$ \\
\hline Mass flow of water vapor in supply air diffuser & Customized from end user & 0.007916 \\
\hline RH for supply air diffuser & Customized from end user & $97 \%$ \\
\hline
\end{tabular}

Table 9: Boundary conditions for the air distribution and return air diffuser boundary conditions.

\begin{tabular}{|c|c|c|}
\hline \multicolumn{2}{|c|}{ Return air diffuser boundary conditions } \\
\hline Parameter & Formulae & Value \\
\hline Area of each supply air diffuser(1 to 30)(Ar) & $(0.4 * 0.4 \pi) / 4$ & $0.12566 \mathrm{~m}^{2}$ \\
\hline Flow rate from each supply diffuser(1 to 30 Fr) & Customized from end user & $0.4 \mathrm{~m}^{3} / \mathrm{s}$ \\
\hline Velocity from each supply diffuser( 1 to 30$)(\mathrm{Vr})$ & Fr/Ar & $3.18 \mathrm{~m} / \mathrm{s}$ \\
\hline
\end{tabular}

Flat supply and return air grills perform a major role in temperature and humidity control, whose boundary conditions are summarized in Tables 10 and 11.

Table 10: Boundary conditions for the air distribution and flat supply air grill boundary conditions

\begin{tabular}{|c|c|c|}
\hline \multicolumn{2}{|c|}{ Flat supply air grill boundary conditions } & Value \\
\hline Parameter & Formulae & $0.6 \mathrm{~m}^{2}$ \\
\hline Area of flat supply air grill (Ar) & $3 * 0.2$ & $0.26 \mathrm{~m}^{3} / \mathrm{s}$ \\
\hline Flow rate from flat supply air grill (Fr) & Customized from end user & $0.43 \mathrm{~m} / \mathrm{s}$ \\
\hline Velocity from flat supply air grill (Vr) & Fr/Ar & \\
\hline
\end{tabular}

Table 11: Boundary conditions for the air distribution and return air diffuser boundary conditions.

\begin{tabular}{|c|c|c|}
\hline \multicolumn{2}{|c|}{ Flat return air grill boundary conditions } \\
\hline Parameter & Formulae & Value \\
\hline Area of flat return air grill (Ar) & $3 * 0.2$ & $0.6 \mathrm{~m}^{2}$ \\
\hline Flow rate from flat return air grill (Fr) & Customized from end user & $0.26 \mathrm{~m}^{3} / \mathrm{s}$ \\
\hline Velocity from flat return air grill (Vr) & $\mathrm{Fr} / \mathrm{Ar}$ & $0.43 \mathrm{~m} / \mathrm{s}$ \\
\hline
\end{tabular}


International Journal of Engineering Research and Technology. ISSN 0974-3154, Volume 13, Number 7 (2020), pp. 1709-1723

(C) International Research Publication House. https://dx.doi.org/10.37624/IJERT/13.7.2020.1709-1723

\subsection{DETAILS OF GREENHOUSE GEOMETRY}

The physical environment determines the equipment selection. Important issues of consideration include greenhouse geometry and location of various tools such as grills and air diffusers.
Developing a model greenhouse using modern software, especially computer aided design (CAD), facilitates visualization, and hence, modeling. Figure 11 shows an example of a model greenhouse using CAD software.

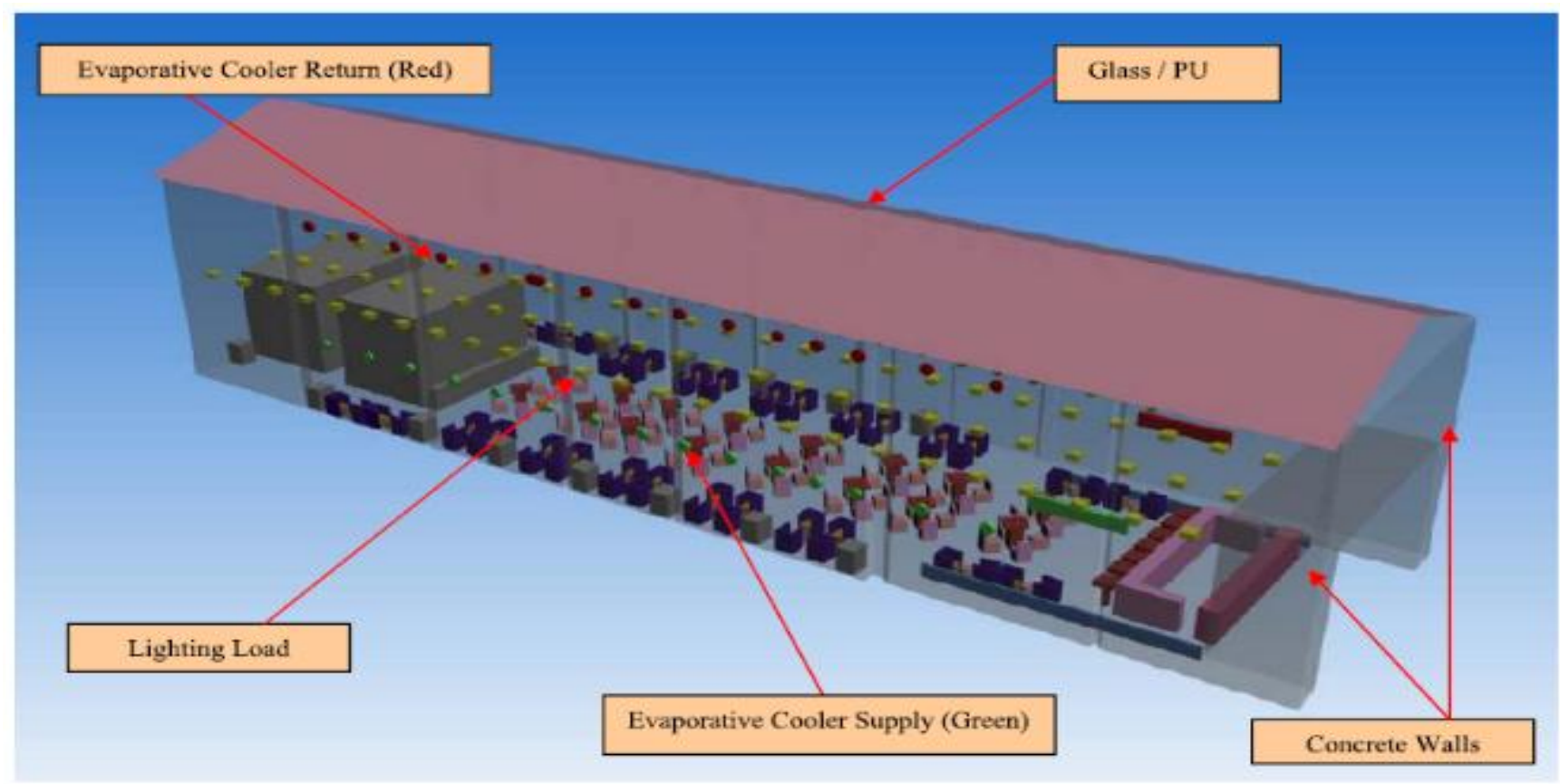

Figure 11: Model greenhouse using CAD

\subsection{CALCULATION OF BOUNDARY CONDITIONS}

The determination of boundary conditions starts with outlining the system details and requirements. Important factors include thermal loads, light intensity, moisture requirements, and air conditioning. Simulation is usually necessary to establish and test the boundary conditions.

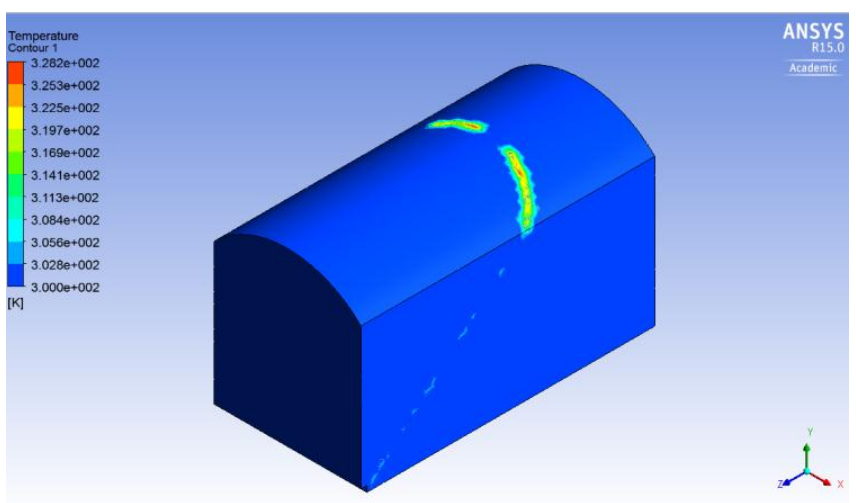

Figure.12a- Temperature distribution at 2.00PM

\subsection{SIMULATION OF CFD AND BOUNDARY CONDITIONS}

CFD simulation involves application of the boundary conditions. Simulation is essential to visualize ways in which the equipment will operate under different conditions. The goal is to establish the best match between the equipment and boundary conditions. Temperature, air velocity, and temperature volume renderings are verified for the climate control module. The major simulation results are summarized in Figure 12.

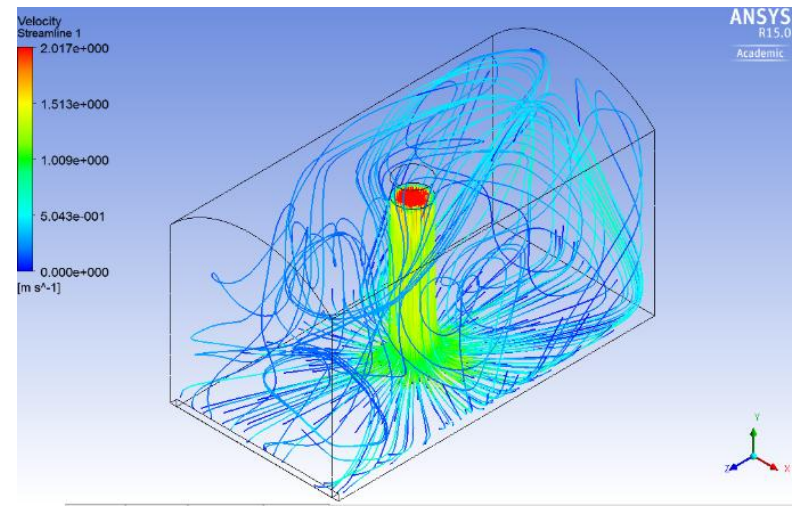

Figure.12b- Velocity profiles at 2.00PM 


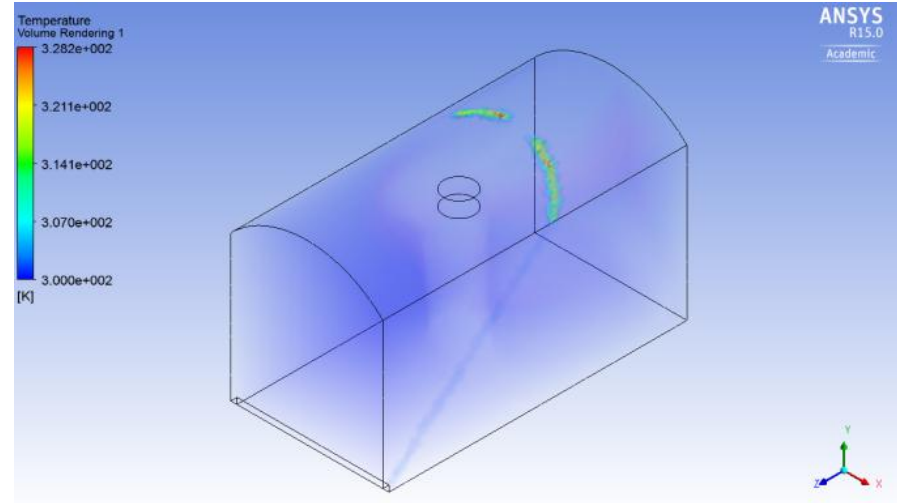

Figure.12c-Temperature rendering profile at 2.00 PM

\subsection{VELOCITY CONTOURS}

Some areas have high velocity, while others have low movements of air. It is imperative to establish velocity profiles as shown below in the figure 12 .

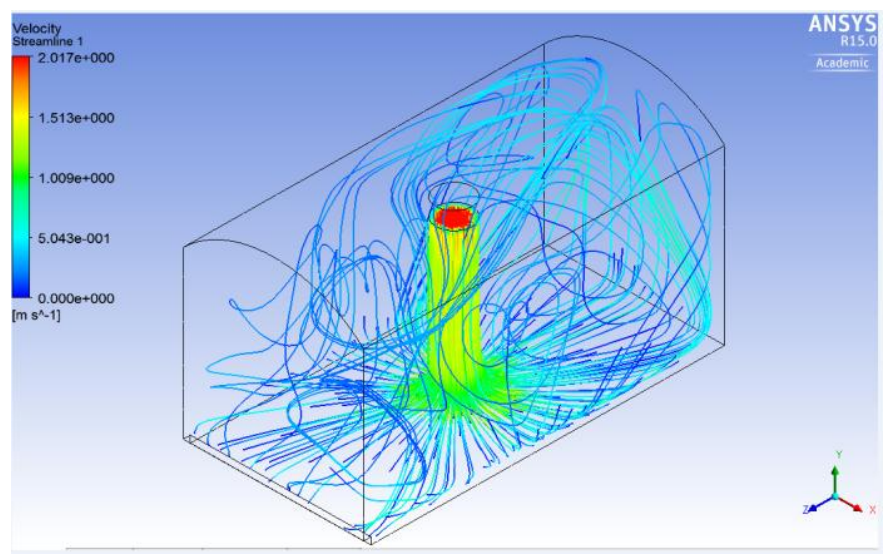

Figure 13: Velocity contours

\subsection{TEMPERATURE DISTRIBUTION THROUGH VOLUME RENDERING}

Figure 13 shows velocity vectors for a greenhouse. Some areas have even distribution, while others are uneven. In the figure, green areas are evenly distributed.

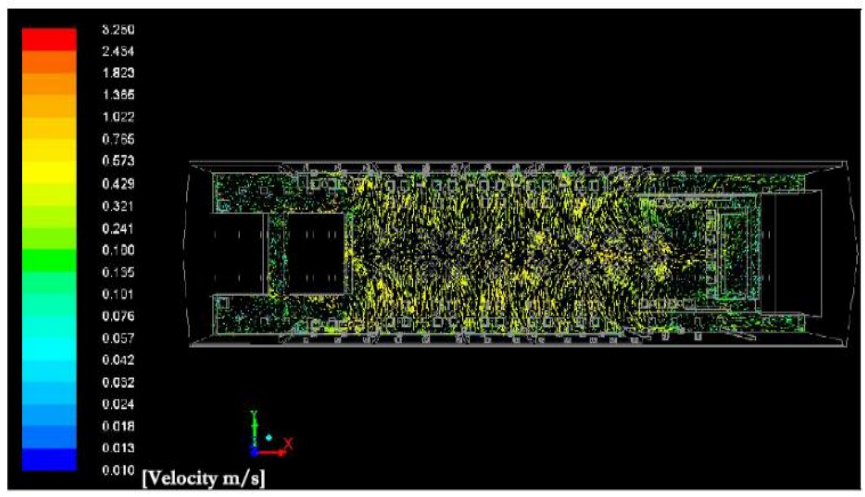

Figure 13: Velocity vectors

\subsection{CONCLUSION}

In this experiment, we established a technologically advanced CMS for a hi-tech commercial greenhouse, comprising a sensor unit, host, and microcontroller for controlling the drip irrigation kit based on data on temperature, radiation, relative humidity, and soil moisture sensors. A Wi-Fi module was used to convey messages between the CMS and base station. We then compared the control system with a conventional one using PLC-based timers, whereby watering was conducted once a day for $15 \mathrm{~min}$. Analysis of data revealed that the CMS with ICS could achieve maximum crop yield while minimizing the resource use. For instance, it achieved up to $30 \%$ savings on water and electricity use. The study findings showed that farmers can optimize greenhouse returns through the use of technology. The expected results were verified using a CFD simulation.

\section{FUTURE WORK}

- Further research on conventional feedback based intelligent controllers.

\section{ACKNOWLEDGMENT}

We would like to provide our sincere gratitude to the entire faculty and students of Birla Institute of Technology and Science Dubai Campus, UAE for all their timely contributions.

\section{NOMENCLATURE}

- HVAC- Heating Ventilation and Air-Conditioning.

- RH- Relative humidity.

- CMS- Climate control system

\section{REFERENCES}

[1] Wang, N., Zhang, N., Wang, M., 2006. Review: Wireless sensors in agriculture and food industry-Recent development and future perspective. Computers and Electronics in Agriculture, 50, 1-14.

[2] Pahlavan, K., Krishnamurthy, P., 2013. Principles of Wireless Access and Localization. John Wiley \& Sons.

[3] Olenewa, J.L., 2014. Guide to Wireless Communications (3rd ed.). Boston, MA: Course Technology Cengage Learning.

[4] Montero, J., Antón, A., Munoz, P., Lorenzo, P., 2001. Transpiration from geranium grown under high temperatures and low humidities in greenhouses. Agric. Forest Meteorol., 323-332.

[5] Fernández, M.D., González, A.M., Carreno, J., Pérez, C., Bonachela, S., 2007. Analysis of on-farm irrigation performance in Mediterranean greenhouses. Agric. WaterManag., 89, 251-260.

[6] Stanghellini, C., 1987. Transpiration of Greenhouse 
International Journal of Engineering Research and Technology. ISSN 0974-3154, Volume 13, Number 7 (2020), pp. 1709-1723

(C) International Research Publication House. https://dx.doi.org/10.37624/IJERT/13.7.2020.1709-1723

Crops (Ph.D. thesis).Wageningen University, Netherlands.

[7]Jemaa, R., Boulard, T., Baille, A., 1995. Some results on water and nutrient consumption of a greenhouse tomato crop grown in rockwool. Acta Hortic., 408, 137-146.

[8] Boulard, T., Wang, S., 2000. Greenhouse crop transpiration simulation from external climate conditions. Agric. Forest Meteorol., 100, 25-34.

[9] Baille, M., Baille, L., Laury, J.C., 1994. A simplified model for predicting evapotranspiration rate of nine ornamental species vs. climate factors and leaf area. Sci. Hortic., 59, 217-232.

[10] Sánchez-Molina, J.A., Rodríguez, F., Guzmán, J.L., Arahal, M.R., 2012. Virtual sensors for designing irrigation controllers in greenhouses. Sensor 44, 1524415266.

[11] Shin, J.H., Park, J.S., Son, J.E., 2014. Estimating the actual transpiration rate with compensated levels of accumulated radiation for the efficient irrigation of soilless cultures of paprika plants. Agric. Water Manag., 135, 9-18.

[12] Vosselen, A.V., Verplancke, H., Ranst, E.V., 2005. Assessing water consumption of banana: traditional versus modelling approach. Agric. Water Manag., 74, 201-218

[13] Gieling, T.H., 2001. Control of Water Supply and Specific Nutrient Application in Closed Growing Systems (Ph.D. thesis). Wageningen University, Netherlands.

[14] McCarthy, A., Hancock, N., Raine, S., 2014. Development and simulation of sensor-based irrigation control strategies for cotton using the VARI wise simulation framework. Comput. Electron. Agric., 101, 148-162.

[15] Harris, T., Mapp, H., 1988. Use of optimal control in deriving water conserving irrigation schedules based on state events. Comput. Electron. Agric., 2, 301-316.

[16] Pawlowski, A., Guzmán, J.L., Berenguel, M., Dormido, S., 2015. Event-based generalized predictive control. In: Event-Based Control and Signal Processing. CRC Press, Boca Raton, USA, pp. 151-176.

[17] Sánchez-Molina, J.A., Rodríguez, F., Guzmán, J.L., Ramírez-Arias, J.A., 2015. Water content virtual sensor for tomatoes in coconut coir substrate for irrigation control design. Agric. Water Manag., 151, 114-125.

[18] Rodríguez, F., Berenguel, M., Guzmán, J.L., RamírezArias, A., 2015. Modeling and Control of Greenhouse Crop Growth. Springer, London, UK.

[19] Kim, Y., Evans, R., Iversen, W., Pierce, F., 2006 a. Instrumentation and control for wireless sensor network for automated irrigation. 2006 ASABE Annual International Meeting. Paper number: 061105.
[20] Kim, Y., Evans, R., Iversen, W., Pierce, F., $2006 \mathrm{~b}$. Evaluation of wireless control for variable rate irrigation. 2006 ASABE Annual International Meeting. Paper number: 062164. [21] Adeyemi, O., Grove, I.P., Norton, T., 2017. Advanced monitoring and management systems for improving in precision irrigation. Sustainability, 9(353), 1-29. doi: 10.3390/su9030353.

[22] Hsieh, M.H., Liu, E.C., Hsu, H.C., Jiang, W.J., Stange, K.W., 2010. Study on drip fertigation used in greenhouse cherry tomato production. Research reports of Tainan District Agricultural Research and Extension Station, 59, 45-53.

[23] Jou, L., Chiu, Y., Fan, L., 2015. Designing the universal type of drip irrigation controller for suitability implemented on irrigation requirement and management of pot plants in greenhouse. Journal of Taiwan Agricultural Engineering, 61(2), 28-46.

[24] Roy, S., Ophori, D., 2014. Estimation of crop water stress index in almond orchards using thermal aerial imagery. Journal of Spatial Hydrology, 12(1), 1-14.

[25] Medrano, E., Lorenzo, P., Sánchez-Guerrero, M.C., Montero, J.I., 2005. Evaluation and modelling of greenhouse cucumber-crop transpiration under high and low radiation conditions. Sci. Hortic., 105, 163-175.

[26] Ponce, P., Molina, A., Cepeda, P., Lugo, E., MacCleery, B., 2015. Greenhouse Design and Control. New York, NY: CRC Press. 